\title{
ORAL ARIPIPRAZOLE FOR THE TREATMENT OF TOURETTE'S SYNDROME IN CHILDREN
}

\author{
Frilya Rachma Putri ${ }^{1}$, Mayniar Ayu Rahmadianti ${ }^{2}$ \\ Correspondence: frilya.putri@gmail.com \\ ${ }^{1}$ Department of Psychiatry, Faculty of Medicine Universitas Brawijaya,${ }^{2}$ Klinik Rawat Inap Pratama NU Talok Malang
}

\section{CASE REPORT}

OPEN ACCESS

\begin{abstract}
Background - Among the pharmacotherapy recommendations for Tourette syndrome (TS), Aripiprazole is a potential treatment option for TS and a relatively safe alternative in the pediatric population.

Case presentation - We report the case of a pediatric patient with TS who was admitted to the hospital after demonstrating severe involuntary movements. The symptoms emerged early in childhood and remained subclinical. It became more noticeable at 3 months before admission when the frequency and the severity started to increase progressively reaching its peak at one month before hospitalization. From further assessment, we found speech delay and a notably high score of Strength and Difficulties Questionnaire (SDQ). At admission of hospitalization, the symptom relieved following of Aripiprazole 1 x $2 \mathrm{mg}$. It significantly diminished to infrequent minor facial tics. There was no adverse effect reported upon hospital discharge. We also performed family psychoeducation and speech therapy as adjuvant therapy.

Conclusions - We selected Aripiprazole because of its unique mechanism of action resulted in a dopamine stabilizer feature with less side effect. The most common ones are nausea, sedation, and increased appetite where, generally, are lessen within 2 weeks. Moreover, in contrast with other antipsychotics, Aripiprazole would not provoke hyperprolactinemia. The more severe side effect such as extrapyramidal symptoms and weight gain are usually dose-dependent at around $10 \mathrm{mg} /$ day. Aripiprazole is also favourable, especially for refractory cases
\end{abstract}

ABSTRACT

Keywords: Tourette syndrome, Tic disorders, Pharmacotherapy, Aripiprazole.

\section{Article History:}

Received: August 28, 2020

Accepted: September 18, 2020

Published: September 28, 2020
Cite this as: Putri, F.R \& Rahmadianti, M.A. Oral aripiprazole for the treatment of Tourette's Syndrome in Children.. Journal of Psychiatry Psychology and Behavioral Research; 2020. 2: 14-15.

\section{INTRODUCTION}

According to Diagnostic and Statistical Manual (DSM) $5,{ }^{1}$ Tourette syndrome (TS) is a child onset neurodevelopmental disorder characterized by both motor and vocal tics which is persisted for at least 1 year. Prevalence of TS is between $0.4 \%$ and $3.8 \%$ for young people between the ages of 5 and 18 years. $^{2}$ It is presumably higher in those with learning difficulties, emotional and behavioural disorders or Autism Spectrum Disorder which most of it has an onset between 4-10 years of age..$^{3,4}$

Even though it has not yet fully understood, hypothetically, abnormal dopamine release underlying the pathophysiology of TS. ${ }^{5}$ Therefore, pharmacotherapy recommendations for TS include haloperidol, risperidone, aripiprazole and other antipsychotics. ${ }^{6}$ Hence, the use of second-generation antipsychotics is preferable because their less side effect compares to first-generation antipsychotics.

Aripiprazole is a second-generation antipsychotic which has a high affinity in dopamine (D2) receptor. It is also a partial agonist of 5HT1A serotonin receptor and strong antagonist of 5HT2A serotonin receptor. With this mechanism of action, aripiprazole has less extrapyramidal symptoms and undesired weight gain. From several case reports, case series, and openlabel trials, aripiprazole indicated as a potential alternative for
TS treatment. ${ }^{7}$ This feature is favored considering the patient in this case report is a female pediatric patient. Aripiprazole is also widely available in Indonesia.

\section{CASE PRESENTATION}

A 4-year old girl, diagnosed with Tourette Syndrome (TS), admitted to the hospital after demonstrating severe involuntary movements. The chief complaint incorporates exaggerated blinking, punching her head, and twisting her body. It is also accompanied by repeated utterance of swear and harsh words. Her family reported histories of occasional tics on her face which was deemed as normal. Consequently, there were no further interventions. The symptoms became more noticeable at 3 months prior to admission when the frequency and the severity started to increase progressively reaching its peak at one month before hospitalization.

From hetero-anamnesis, the escalation of motor and vocal symptoms subsequently manifested after her parents got divorced 3 months ago. During this transitional phase, her mother became more emotional and irritable thus frequently vented her frustration toward the child. It took a toll on their already tenuous relationship. Therefore, the girl has more proximity with her grandmother rather than her mother. 
The assessment of growth and development detected no physical abnormality but revealed speech delay where she only has a limited vocabulary and has not been able to say complete sentences in age 4 . However, she seems to comprehend the context of the conversation thus understand words and sentences as well as can follow simple directions. From the Strength and Difficulties Questionnaire (SDQ), she scored a quite high total score of 17 indicates a substantial risk of clinically significant problem in the area of hyperactivity and peer problems.

At the time of hospitalization, the patient demonstrated clinical improvement following the admission of Aripiprazole with an initial dose of 1 x $2 \mathrm{mg}$. It significantly diminished to infrequent minor facial tics and in addition, there was no adverse effect reported upon hospital discharge. There will be a periodical assessment of Aripiprazole dose, clinical improvement, side effect, and comorbid for this patient and will be managed accordingly. Aripiprazole therapy will be maintained minimum one-year period. We also performed family psychoeducation and speech therapy as adjuvant therapy.

\section{DISCUSSION}

In this case, we chose not to utilize alpha-2-adrenoreceptor agonist such as clonidine or guanfacine despite being first-line therapy for TS. The main reason was that the patient presented relatively severe symptoms upon admission. Consequently, we required a more potent agent for this case where clonidine or guanfacine fail to meet this necessity. Roessner et al. stated that these agents have smaller tic-suppressing potency compared to antipsychotic drugs. ${ }^{8}$ Further, it also stated that tic reduction was present in patients with tics and comorbid Attention Deficit and Hyperactivity Disorder (ADHD) but not those without. European clinical guidelines for Tourette syndrome and other tic disorder also confirmed this statement. ${ }^{9}$

In contrast, we selected Aripiprazole based on the rationale that this second-generation of antipsychotic is a prospective option for TS because of its partial D2 agonist of dopamine receptors. Theoretically, it reduces the release of dopamine when the level concentrations are high and rises dopamine output when the level concentrations are diminished. ${ }^{10}$ This unique mechanism of action resulted in a dopamine stabilizer feature of Aripiprazole with less side effect. The most common ones are nausea, sedation, and increased appetite where, generally, are lessen within 2 weeks. ${ }^{9}$ Moreover, in contrast with other antipsychotics, Aripiprazole would not provoke hyperprolactinemia. ${ }^{11}$ The more severe side effect such as extrapyramidal symptoms and weight gain are usually dosedependent at around $10 \mathrm{mg} /$ day. Aripiprazole is also favourable especially for refractory cases. ${ }^{9}$

During hospitalization, the girl responded to the therapy very well with a relatively small dose of Aripiprazole shown by the reduction of main symptoms and reported no adverse effect. Regular follow-up will measure the patient's symptoms, relapse, or emerging side effects. Appropriate management will be done accordingly.

\section{CONCLUSION}

Based on this case presentation, aripriprazole can be choosen as psychopharmacy for Tourette's syndrome in child. The limitation from this study related with duration of follow up and need to involve similar case in population.

\section{Conflict of interest}

No conflict of interest in this study.

\section{References}

1. American Psychiatric Association. Diagnostic and Statistical Manual of Mental Disorders (5th ed). Washington, DC; 2013.

2. Lewis M, editor. Child and Adolescent Psychiatry: a Comprehensive Textbook. 4th ed. Philadelphia: Lippincott Williams \& Wilkins; 2007. 1200 p.

3. Hollis C, Pennant M, Cuenca J, Glazebrook C, Kendall T, Whittington $\mathrm{C}$, et al. Clinical effectiveness and patient perspectives of different treatment strategies for tics in children and adolescents with tourette syndrome: A systematic review and qualitative analysis. Health Technol Assess (Rockv). 2016;20(4).

4. Dale RC. Tics and Tourette: A clinical, pathophysiological and etiological review. Curr Opin Pediatr. 2017;29(6):66573.

5. Cui YH, Zheng Y, Yang YP, Liu J, Li J. Effectiveness and tolerability of aripiprazole in children and adolescents with Tourette's disorder: A pilot study in China. J Child Adolesc Psychopharmacol. 2010;20(4):291-8.

6. Liu Y, Ni H, Wang $\mathrm{C}$, Li L, Cheng Z, Weng Z Effectiveness and Tolerability of Aripiprazole in Children and Adolescents with Tourette's Disorder: A MetaAnalysis. J Child Adolesc Psychopharmacol [Internet]. 2016;26(5):436-41. Available from: http://online.liebertpub.com/doi/10.1089/cap.2015.0125

7. Zheng W, Li X-B, Xiang Y-Q, Zhong B-L, Chiu HFK, Ungvari GS, et al. Aripiprazole for Tourette's syndrome: a systematic review and meta- analysis. Hum Psychopharmacol. 2017;31:11-8.

8. Roessner V, Schoenefeld K, Buse J, Bender S, Ehrlich S, Münchau A. Pharmacological treatment of tic disorders and Tourette Syndrome. Neuropharmacology [Internet]. 2013;68:143-9. Available from: http://dx.doi.org/10.1016/j.neuropharm.2012.05.043

9. Roessner V, Plessen KJ, Rothenberger A, Ludolph AG, Rizzo R, Skov L, et al. European clinical guidelines for Tourette syndrome and other tic disorders. Part II: Pharmacological treatment. Eur Child Adolesc Psychiatry. 2011;20(4):173-96.

10. Stahl SM. Stahl's Essential Psychopharmacology: Neuroscientific Basis and Practical Applications-4th ed. New York: Cambridge University Press; 2013.

11. Janik P, Szejko N. Aripiprazole in treatment of Gilles de la Tourette syndrome - New therapeutic option. Neurol Neurochir Pol [Internet]. 2018;52(1):84-7. Available from: http://dx.doi.org/10.1016/j.pjnns.2017.10.015 